\title{
Modos de uso de pesquisa-ação em Dissertações e Teses em Administração no Brasil
}

\author{
Modes of Use of Action \\ Research in Dissertations and \\ Theses in Administration in Brazil
}

\author{
ROGÉRIO ZANON DA SILVEIRA \\ Universidade Federal do Espírito Santo \\ MARCIA PREZOTTI PALASSI \\ Universidade Federal do Espírito Santo \\ ANA PAULA PAES DE PAULA \\ Universidade Federal do Minas Gerais
}

\section{RESUMO}

Este artigo se orienta pelo seguinte problema de pesquisa: como o método de pesquisa-ação vem sendo utilizado em investigações nos programas de pós-graduação em mestrado e doutorado no Brasil? O objetivo é investigar os tipos de pesquisa-ação predominantes nesses trabalhos. O referencial teórico provém do entendimento de Thiollent (2011) de pesquisa-ação. Trata-se de uma pesquisa bibliográfica realizada durante os anos de 2018 e 2019, em 64 dissertações e teses defendidas no período de 2011 a 2018 nos programas de pós-graduação em administração brasileiros. As informações obtidas foram submetidas à Análise de Conteúdo, utilizando-se as categorias definidas por Tripp (2005) de pesquisa-ação: técnica; prática; política; socialmente crítica; e emancipatória. Os resultados revelam um forte predomínio da visão técnica e prática de pesquisa-ação e pouca utilização nos sentidos político e crítico-social, o que vai ao encontro da visão hegemônica funcionalista no campo da Administração. As contribuições do artigo são esclarecimentos sobre o uso da pesquisa-ação, bem como orientações para a exploração de novas tipologias. Palavras-chave: Pesquisa-ação. Metodologias participativas. Administração. 


\section{Abstract}

This article is guided by the following research problem: How has the action research method been used in research in postgraduate masters and doctorate programs in Brazil? The objective is to investigate the predominant types of action research in these works. The theoretical framework comes from Thiollent's (2011) understanding of action research. This is a bibliographical research carried out in 2018 and 2019, in 64 dissertations and theses defended in the period from 2011 to 2018 in Brazilian post-graduate programs in administration. The data were submitted to Content Analysis using the categories defined by Tripp (2005): technique; practice; policy; socially critical; and emancipatory. The results show a strong predominance of the technical and practical vision of action research and little use in the political and social-critical senses, in keeping with the functionalist hegemonic vision in the field of Administration. The contributions of the article are clarifications on the use of action research, as well as guidelines for the exploration of new typologies.

Keywords: Action research. Participatory methodologies. Administration.

\section{INTRODUÇÃo}

Este artigo se orienta pelo seguinte problema de pesquisa: como o método de pesquisa-ação vem sendo utilizado em investigações nos programas de pós-graduação em mestrado e doutorado no Brasil? O objetivo é investigar os tipos de pesquisa-ação predominantes nesses trabalhos. O processo de desenvolvimento da Administração como ciência deu-se num tempo de evidência do positivismo, que influenciou o modo como são tratadas questões ontológicas, epistemológicas, metodológicas e éticas. O modelo positivista foi se afirmando hegemônico, mas, recentemente, observa-se uma ênfase crescente de pesquisas com cunho interpretativista, baseadas na fenomenologia, na etnografia, no interacionismo simbólico e na grounded theory, conforme salientam Novaes e Gil (2009).

A pesquisa-ação também começa a ganhar mais espaço na área inspirada em diversas matrizes teóricas. Todavia, conforme Baldissera (2001), a intervenção na realidade e a ação educativa e consciente 
dos envolvidos no processo de pesquisa é seu principal diferencial. Segundo o autor, a pesquisa científica dos processos sociais, em termos objetivos ou subjetivos, requer trabalhar o objeto de estudo de forma interdisciplinar, mas voltada à tomada de consciência coletiva direcionada a uma ação determinada, “(...) também coletiva, na busca dos interesses dos envolvidos na pesquisa, ou seja, pesquisadores, pesquisados e comunidade" (BALDISSERA, 2001, p. 25).

Existem variações consideráveis de nomes e conceitos em torno da pesquisa-ação, gerando naturalmente confusão. Teixeira e Megid Neto (2018) pesquisaram o uso da pesquisa-ação em dissertações e teses no ensino de Biologia, concluindo que é baixo o número de pesquisas dessa natureza nesse campo. Também observaram confusão em torno de definições e conceitos de pesquisa-ação na literatura especializada. De modo semelhante, Paredes-Chi e Castilho-Burguete (2018a) realizaram ensaio refletindo sobre a persistência de confusão em torno de conceitos e definições de pesquisa-ação participante, dado que em seu lugar há outras denominações utilizadas pelos pesquisadores, como pesquisa participativa e pesquisa-ação. Os autores consideram, que independentemente do tipo de nome dado a esse modo de pesquisa, é importante ter sempre em mente os elementos axiológicos, empíricos e filosóficos que o fundamenta.

Melo, Osterne e Chaves (2016) observam que a pesquisa-ação pode ser entendida epistemologicamente como um modo de pesquisa qualitativa, pois os conhecimentos que pretende obter somente podem ser revelados a partir da interação entre os seres humanos. Lembram também esses autores o consenso entre teóricos da pesquisa qualitativa de que o pesquisador é o principal sujeito no processo de observação e construção do conhecimento (GONZÁLEZ REY, 2002; VIEIRA; CASTRO; OLIVEIRA, 2013; GONZÁLEZ REY e MARTINEZ, 2017), e de que a pesquisa-ação está associada à ideia de pesquisa qualitativa no sentido de que determinado fenômeno social objeto de pesquisa revela-se ao pesquisador quando ele se engaja pessoalmente através da observação, diagnóstico e intervenção no processo de pesquisa (Lewin, 1965).

Neste artigo, adota-se o referencial teórico de Thiollent (2011), em seu entendimento de que pesquisa-ação é um tipo de investigação voltada para a solução de problemas técnicos e sociais, rele- 
vantes cientificamente, pautada na cooperação entre pesquisadores, pessoas da situação-problema e parceiros interessados na sua resolução, construindo conhecimento durante este processo.

O artigo baseia-se em uma pesquisa bibliográfica realizada durante os anos de 2018 e 2019 no Banco de Teses e Dissertações da Coordenação de Aperfeiçoamento de Pessoal de Nível Superior - CAPES. Nessa busca virtual, podem ser encontrados 68 trabalhos defendidos nos programas de pós-graduação em Administração brasileiros, no período de 2011 a 2018, a partir da palavra-chave "pesquisa-ação" no endereço na internet http://catalogodeteses.capes.gov.br. Tendo em vista o objetivo da pesquisa, a opção foi por analisar as dissertações e teses, ao invés dos artigos publicados em revistas derivados desses trabalhos, porque há maior detalhamento da metodologia utilizada, fornecendo informações relevantes para se compreender a utilização da pesquisa-ação. Neste trabalho, esses trabalhos foram submetidos à Análise de Conteúdo (BARDIN, 2004) com base na tipologia de pesquisa-ação proposta por Tripp (2005): técnica; prática; política; socialmente crítica; e emancipatória.

Os resultados revelam uma riqueza de experiências nas categorias estudadas, mas também um forte predomínio da visão técnica e prática de pesquisa-ação, com pouca utilização nos sentidos político, crítico-social e emancipável, resultados que vão ao encontro da visão hegemônica funcionalista no campo da Administração.

Este artigo está organizado em cinco partes. A primeira é esta introdução apresentando o tema, o problema e o objetivo do trabalho. A segunda parte descreve o referencial teórico, baseado principalmente nos estudos de Thiollent (2011) e nas tipologias de Tripp (2005) para a pesquisa-ação. A terceira parte explica a metodologia, a pesquisa bibliográfica e as etapas para alcance do objetivo. A quarta parte apresenta os resultados e interpretações. E a quinta parte expõe as considerações finais, apontando possíveis contribuições da pesquisa para a Administração e sugestão de novas pesquisas.

\section{REFERENCIAL TEÓRICO}

A pesquisa-ação tem sido objeto de investigação teórica por inúmeros estudiosos: Barbier (2007); Haguette (1997); Bogdan e Biklen (1994); Triviños (1992); Thiollent (1998; 2011); e Tripp (2005), 
entre outros. Esses autores consideram a pesquisa-ação uma abordagem qualitativa, tendo em vista que informações e conhecimentos obtidos a partir do método possuem natureza descritiva e riqueza de significados. Bogdan e Biklen (1994, p. 16), por exemplo, ressaltam que na abordagem qualitativa a investigação não é feita visando obtenção de respostas a questões previamente formuladas, ou para verificar hipóteses levantadas, pois os pesquisadores devem privilegiar compreender comportamentos e fenômenos a partir da perspectiva dos sujeitos da pesquisa. Assim, "as causas exteriores são consideradas de importância secundária". Ou seja, informações são obtidas por meio de contato aprofundado com as pessoas em seus espaços sociais onde se realiza a investigação.

Um tema que tem merecido atenção de muitos pesquisadores é a relação entre o desenvolvimento da atividade de professor e de pesquisador e a pesquisa-ação, algo também presente nas interpretações das dissertações e teses objeto deste artigo. A título de ilustração, foram selecionados alguns trabalhos recentes que tratam sobre esse tema nos últimos anos, mostrando potencialidades da pesquisa-ação na docência e na pesquisa acadêmica.

Durak et al (2016), ao analisarem pesquisas de mestrado e doutorado usando a pesquisa-ação na Turquia, chegaram à conclusão de que essa metodologia influencia positivamente na educação. Burns e Westmacott (2018) se aprofundam mais no tema e chamaram atenção para os desafios que muitas universidades enfrentam para auxiliar professores a se tornarem pesquisadores. Os autores estudaram, numa universidade privada de ensino no Chile, um programa desenvolvido através da pesquisa-ação para auxiliar professores a se envolverem em pesquisa científica.

Paredes-Chi e Castilho-Burguete (2018b) questionaram se é possível considerar a pesquisa-ação-participativa uma ação alternativa pedagógica inovadora para a formação de professores como pesquisadores. Os resultados da pesquisa indicaram que essa opção se apresenta inovadora na formação de professores na condução de pesquisas, contribuindo para sua melhor preparação em assumir tarefas e responsabilidades em escolas de ensino médio no México.

Yigit e Bagceci (2017) obtiveram opinião de professores sobre a contribuição da pesquisa-ação para seu desenvolvimento profissional 
numa escola primária e média estadual e os resultados mostraram impacto positivo em vários aspectos de progresso profissional como docente. Em sentido parecido, Fulmer, Chu e Martin (2018), em editorial, refletiram sobre o potencial da pesquisa-ação para a promoção de inovações educacionais e autodesenvolvimento de professores em Cingapura, onde o uso do método tem sido enfatizado ao longo dos últimos quinze anos. Na visão dos autores, a pesquisa-ação não consiste apenas em ferramenta para o desenvolvimento profissional e melhoria dos trabalhos de aula, mas poderia servir como uma esteira no envolvimento de professores em pesquisas com bolsa de estudos. O potencial reside na possiblidade dos professores se autodesenvolverem como sujeitos praticantes reflexivos, líderes e pesquisadores.

Na visão de Kemmis e McTaggart (2005), na pesquisa-ação participativa estão envolvidos tanto os pesquisadores quanto participantes da comunidade estudada. No processo de investigação, esses sujeitos transformam a si mesmos e as próprias técnicas e métodos que utilizam. Assim, o processo de pesquisa não se caracteriza pela aplicação de técnicas pré-definidas ao problema investigado, mas pela construção e desenvolvimento de métodos e técnicas de pesquisa.

Neste trabalho, é enfatizada a definição de Thiollent (2011) de pesquisa-ação como um tipo de pesquisa social associada a uma ação ou à resolução de um problema coletivo, na qual pesquisadores e participantes de uma situação investigada envolvem-se de forma cooperativa e participativa. Amiúde, a pesquisa-ação é vista como forma de engajamento sócio-político a serviço de causas mais populares. Todavia, ela também é discutida em áreas de atuação técnica ou organizacional, alinhadas a compromissos sociais ou ideológicos, gerando propostas de pesquisas em diferentes campos de atuação social.

Thiollent (2011) defende que, para cumprir seu objetivo no sentido de estabelecer relação entre conhecimento e ação entre pesquisadores e pessoas envolvidas numa situação investigada, e uma relação dessas pessoas com a realidade, faz-se necessário o desenvolvimento de ampla interação entre pesquisadores e envolvidos na pesquisa. Com a pesquisa-ação, o que se pretende é ampliar o conhecimento do pesquisador, bem como o conhecimento e o nível de conscientização de pessoas e grupos que participam do processo 
de pesquisa, visando contribuírem para a discussão ou avançarem nas questões abordadas.

Thiollent (2011) apresenta a pesquisa-ação como estratégia metodológica de pesquisa social que:

- exige ampla e explícita interação entre pesquisadores e pessoas implicadas na situação pesquisada, interação que resulta na priorização de problemas a serem investigados e também, nas soluções a serem encaminhadas na forma de ação concreta;

- tem como objetivo de pesquisa a situação social e problemas de diferentes naturezas encontrados nessa situação, mas não as pessoas;

- tem também, como objetivo, resolver ou ao menos, esclarecer os problemas da situação observada;

- abrange um processo de acompanhamento das decisões das ações e da atividade intencional das pessoas envolvidas na situação;

- não se limita a uma forma de ação e ao ativismo, pois contempla a pretensão de aumento de conhecimento ou de esclarecimento por parte do pesquisador e das pessoas envolvidas na situação objeto de pesquisa.

Os objetivos da pesquisa-ação podem ser resumidos em dois: um objetivo prático e outro objetivo de conhecimento ou esclarecimento. Thiollent (2011) também, enumera alguns passos da pesquisa-ação: 1) diagnóstico ou fase de exploração; 2) realização de seminários; 3) definição do tema da pesquisa; 4) colocação dos problemas; 5) definição do lugar da teoria; 6) definição de hipóteses; 7) definição do campo de observação e amostragem; 8) obtenção de informações; 9) interpretação das informações (ou dados); 10) plano de ação; e 11) avaliação dos resultados. A pesquisa-ação, na visão de Paes de Paula (2015, p. 271), é

(...) uma estratégia científica aberta, que recorre à forma de experimentação, mas que ocorre em situação real, sem possibilidade de isolar variáveis, opondo-se ao positivismo. É também uma estratégia de pesquisa dialógica, remetendo à autorreflexão coletiva e à ação comunicativa de Jürgen Habermas, na medida em que apresenta características que são próprias dos processos argumentativos e deliberativos. 
Baldissera (2001, p. 7) enfatiza que a pesquisa-ação, como método de pesquisa, reúne variadas técnicas de pesquisa social, valendo-se de mecanismos de coleta e interpretação de dados, “(...) de intervenção na solução de problemas e organização de ações, bem como de técnicas e dinâmicas de grupo para trabalhar com a dimensão coletiva e interativa na produção do conhecimento e programação da ação coletiva".

Alguns autores investigaram formas de uso da pesquisa-ação em seus campos de estudo. Chiasson, Germonprez e Mathiassen (2009), por exemplo, revisaram artigos publicados em revistas especializadas na área de sistemas de informação para explorar como pesquisadores nesse campo praticam a pesquisa-ação. Os autores concluíram que os pesquisadores do campo de sistemas de informação utilizavam a pesquisa-ação mesclada a outros métodos de pesquisa, compondo um portfólio rico de abordagens para produção de conhecimento.

A pesquisa-ação ou investigação-ação tem origem nas ciências sociais, tendo sido introduzida no Brasil no campo da educação e do planejamento rural pelo sociólogo brasileiro João Bosco Guedes Pinto, visando incentivar a participação de moradores e produtores em áreas rurais nos processos de planejamento e desenvolvimento local. As ideias de Pinto (1989) fundamentam-se no Método de Educação Libertadora de Paulo Freire, que rejeita a educação tradicional baseada meramente no "ler e escrever", para defender e incentivar o posicionamento da pessoa não alfabetizada no meio social e político onde vive, ou seja, o posicionamento do adulto em seu contexto real (BALDISSERA, 2001).

Em sentido parecido, Khan, Bawani e Aziz (2013) indagam sobre o real propósito do conhecimento. Seria apenas um produto final ou meio para ação e mudanças? A partir de uma pesquisa realizada no Paquistão intitulada Women's Empowerment in Muslim Contexts (WEMC) (Empoderamento das Mulheres em Contextos Muçulmanos), os autores argumentam que estudos baseados na pesquisa-ação fornecem uma ponte entre a separação que existe entre conhecimento e ação. Os autores se inspiram em Paulo Freire, para ressaltarem os propósitos de seu artigo: 
It proposes, especially, in resource poor countries, combining health research with Paolo Freire's view of participation and change; and sees action by research participants as an outcome of the development of their critical consciousness (KHAN, BAWANI e AZIZ, 2013, p. 157).

Macke (2006) faz um panorama aberto e completo da pesquisa-ação identificando suas bases filosóficas voltadas a uma filosofia da ação e do conhecimento, em que o conhecimento estaria a serviço da ação e de processos de mudança. A autora ainda faz referência a visões sobre a pesquisa-ação como uma variante do estudo de caso, ou como um método que supera o estudo de caso. Argyris e Schön (1974) sustentam essa segunda visão, ao dizerem que, na pesquisa-ação, quando os participantes de uma investigação estão envolvidos num processo de mudança, esse envolvimento os faz pensar e refletir sobre o que estão praticando. São essas e outras reflexões sobre a pesquisa-ação que redundam em diferentes modalidades de aplicação dessa técnica de investigação. Neste trabalho, adota-se os estudos de Tripp (2005), que identifica cinco tipos ou visões de pesquisa-ação: técnica; prática; a política; socialmente crítica; e emancipatória.

Para o autor, a pesquisa-ação técnica constitui abordagem pontual, em que o pesquisador toma uma prática adotada num outro lugar e procura implementá-la em seu ambiente pesquisado, visando realizar alguma melhoria: "Ela é 'técnica' porque o pesquisador está agindo de modo inteiramente mecânico: de fato, está "seguindo o manual" (Tripp, 2005, p. 457). Já a pesquisa-ação prática diferenciase da técnica porque o pesquisador escolhe ou projeta mudanças realizadas, porém sem seguir especificamente um "manual".

Nesse caso, as duas características distintivas são: 1) é mais como a prática de um ofício - o artífice pode receber uma ordem, mas o modo como alcança o resultado desejado fica mais por conta de sua experiência e ideias; e 2) porque o tipo de decisões que ele toma sobre o quê, como e quando fazer são informadas pelas concepções profissionais que tem sobre o que será melhor para seu grupo. Os artífices estabelecem seus próprios critérios para qualidade, beleza, eficácia, durabilidade e assim por diante. Assim, em educação, por exemplo, o pesquisador tem em mira contribuir para 
o desenvolvimento das crianças, o que significa que serão feitas mudanças para melhorar a aprendizagem e a autoestima de seus alunos, para aumentar o interesse, a autonomia ou cooperação e assim por diante (Tripp, 2005).

A pesquisa-ação política está associada à mudança de cultura, pois intenta mudar ou compreender limitações de uma cultura sobre a ação. É necessário, então, engajamento na política para mudar um sistema, o que somente pode ser feito através de exercício do poder, por isso, tal ação se torna política. Tripp (2005) exemplifica muitos modos de exercício do poder, como o poder de fazer com que pessoas trabalhem juntas; ou o poder de fazer algo quando outros não observam; ou o poder de superar argumentações opostas. Pode-se observar, trata-se de uma visão oposta à da pesquisa-ação em sentido de emancipação.

Já a pesquisa-ação socialmente crítica é vista por Tripp (2005, p. 458) como um tipo particular de pesquisa-ação política e ambas se sobrepõem, pois “(...) quando se trabalha para mudar ou para contornar as limitações àquilo que você pode fazer, isso comumente é resultado de uma mudança em seu modo de pensar a respeito do valor último e da política das limitações". Nesse caso, o pesquisador busca fazer algo melhor do que já foi feito, mas comprometido com a transformação do mundo em termos de justiça social.

Geralmente, a ideia de transformação e de justiça social que aparece é definida na literatura por mudanças, tais como: aumento de igualdade e oportunidade; melhor atendimento às necessidades das pessoas; tolerância e compreensão com os outros; cooperação maior e mais eficiente; maior valorização das pessoas (de si mesmo e dos outros); etc. Para Tripp (2005, p. 458), “(...) a pesquisa-ação socialmente crítica passa a existir quando se acredita que o modo de ver e agir 'dominante' do sistema, dado como certo relativamente a tais coisas, é realmente injusto de várias maneiras e precisa ser mudado".

Por fim, Tripp (2005, p. 458) identifica o que chama de uma outra variante da pesquisa-ação política, que denomina de pesquisa-ação emancipatória. Esse tipo de pesquisa carrega em si a proposta de “(...) mudar o status quo não só para si mesmo e para seus companheiros mais próximos, mas de mudá-lo numa escala mais ampla, do grupo social como um todo". Como exemplo o autor 
lembra que "as sufragistas" não reivindicavam apenas o direito ao voto para si, mas para que todas as mulheres tivessem o mesmo direito. Portanto, a pesquisa-ação emancipatória é mais ampla, constituindo-se num esforço participativo e colaborativo, algo que é socialmente crítico por sua própria natureza.

\section{Metodologia}

Este artigo é derivado de uma pesquisa bibliográfica feita no Banco de Teses e Dissertações da Capes durante. Nessa busca, foram encontrados 68 trabalhos, dentre os quais 64 foram selecionados em conformidade com o objetivo de pesquisa, sendo 45 dissertações e 19 teses, defendidas no período de 2011 a 2018 nos programas de pós-graduação em Administração brasileiros, cuja relação consta no apêndice deste artigo. Estabeleceu-se como marco inicial de pesquisa o ano de 2011, pois a partir dessa data o banco de dados possibilitou acesso ao trabalho completo. Trabalhos defendidos a partir de 2019 não estavam disponíveis no Banco de Teses da CAPES até a finalização deste artigo, em setembro de 2019.

As informações obtidas foram interpretadas à luz da Análise de Conteúdo (BARDIN, 2004). As categorias de análise foram previamente estabelecidas, tomando-se como referência as cinco modalidades de pesquisa-ação estudadas por Tripp (2005), apresentadas no referencial teórico. Na leitura das dissertações e teses, procurou-se atentar para a aproximação entre a intenção do pesquisador em adotar a pesquisa-ação e sua adoção de fato na pesquisa.

A pesquisa foi realizada em seis etapas. A primeira consistiu na busca eletrônica do vocábulo "pesquisa-ação" no resumo de dissertações e teses defendidas em programas de pós-graduação brasileiros disponíveis no site bancodeteses.capes.gov.br que a partir de 2017 passou a se chamar catalogodeteses.capes.gov.br. A segunda fase foi a leitura prévia desses trabalhos. Na terceira fase, por meio de uma leitura mais aprofundada, buscou-se a interpretação à luz das categorias pré-estabelecidas por Tripp (2005).

Adicionalmente, foi realizada busca na base de dados Scielo para mostrar um panorama quantitativo da publicação científica sobre pesquisa-ação no Brasil nas últimas décadas. O objetivo dessa busca foi somente contextualizar o objeto de pesquisa e mostrar como 
a área de Administração se insere nesse contexto, apresentado no início do capítulo de interpretações e resultados.

A quarta etapa consistiu na classificação desses resumos por categoria e na concatenação desses trabalhos para possibilitar comparações entre resumos de uma mesma categoria. Na quinta etapa, procedeu-se à elaboração de um texto de resultados exposto na quarta seção deste artigo. A sexta etapa consistiu na formatação final deste artigo e na elaboração das considerações finais.

\section{INTERPRETAÇõES E RESULTADOS}

O panorama sobre publicação científica no Brasil abordando o tema pesquisa-ação revela um crescimento nos últimos trinta anos, que se estabilizou nos últimos dez anos, sendo que o campo da Administração aparece com destaque. É o que mostra o portal de periódicos na internet Scientific Electronic Library Online (Scielo), base escolhida para obtenção do panorama da publicação em pesquisa-ação no Brasil, pelo número que apresenta em termos de publicação e de acesso. Em 2018, foram acessados na Scielo mais de dez milhões de documentos em formato pdf nos quatrocentos periódicos científicos abrangidos pelo portal, nos mais diferentes campos de pesquisa, números que aportam representatividade à noção que se pretende ter nesta pesquisa sobre o uso da pesquisa-ação no Brasil.

Pesquisa realizada na página da Scielo na internet, no dia 25/07/2018, quando iniciado este artigo, retornou informação de que foram publicados 3.996 artigos em periódicos científicos no Brasil no campo das ciências sociais aplicadas de 1994 a 2018. A área da Administração contribui expressivamente para essa publicação: dos vinte periódicos que mais publicaram sobre o tema, oito são do campo da Administração. Chama também atenção a quantidade de artigos publicados por essas revistas em Administração, ao todo, 1.904 trabalhos, quase a metade do total de 3.996 trabalhos publicados, como mostra a Tabela 1. 


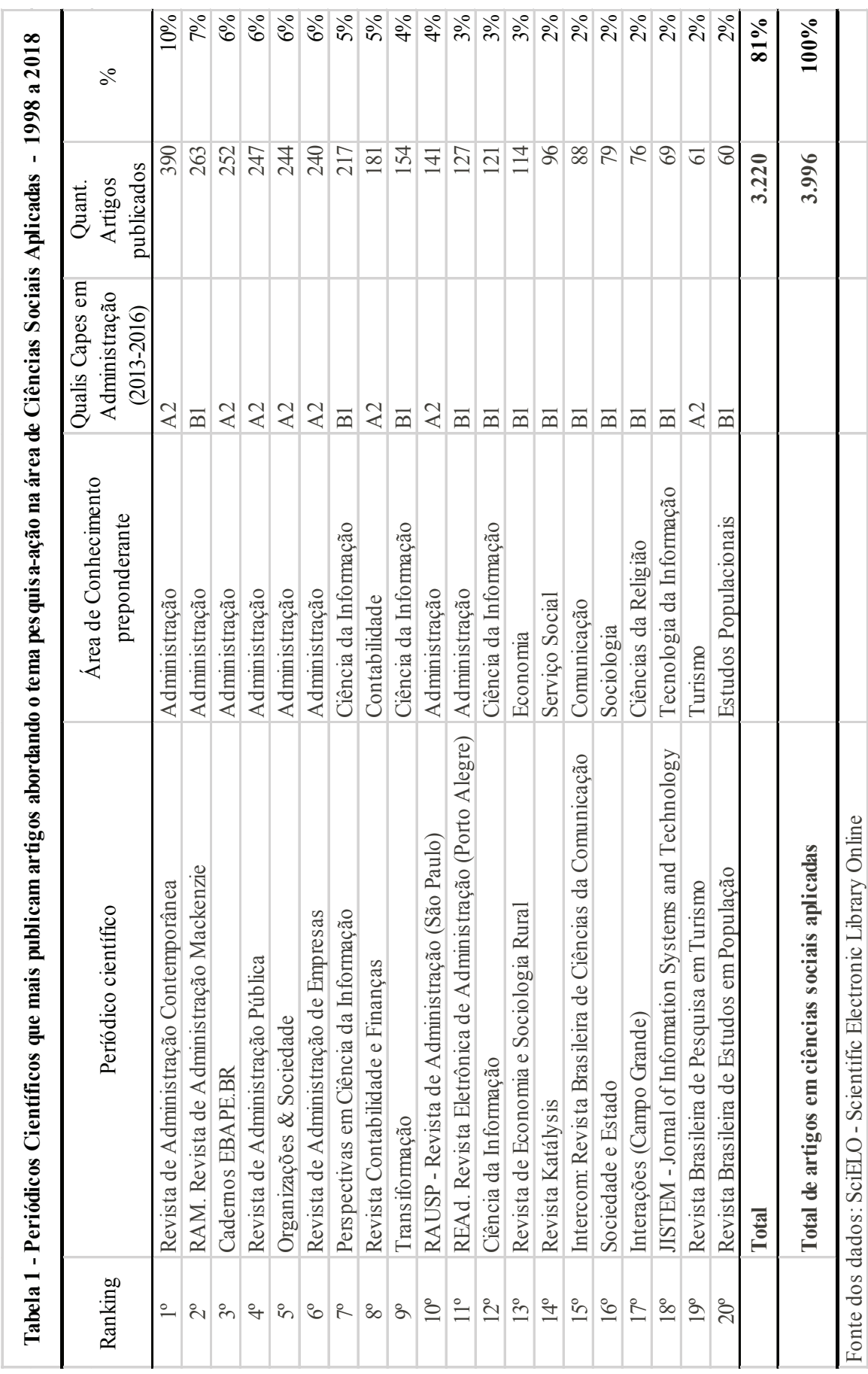


Dos vinte periódicos que mais publicam, oito deles têm conceito A2 na classificação feita pela CAPES, o Qualis Capes, sendo que destes, sete são da área de Administração. Apesar do número expressivo de 3.562 periódicos conceituados pelo Qualis Capes, observase concentração das publicações sobre pesquisa-ação num número pequeno de revistas científicas. Do total de artigos publicados no campo das ciências sociais aplicadas sobre pesquisa-ação, nas vinte revistas apresentadas na Tabela 1, estão concentradas mais de oitenta por cento das 3.996 publicações no período de 1998 a 2018. E entre essas vinte revistas, oito periódicos em Administração concentram aproximadamente a metade dos artigos publicados.

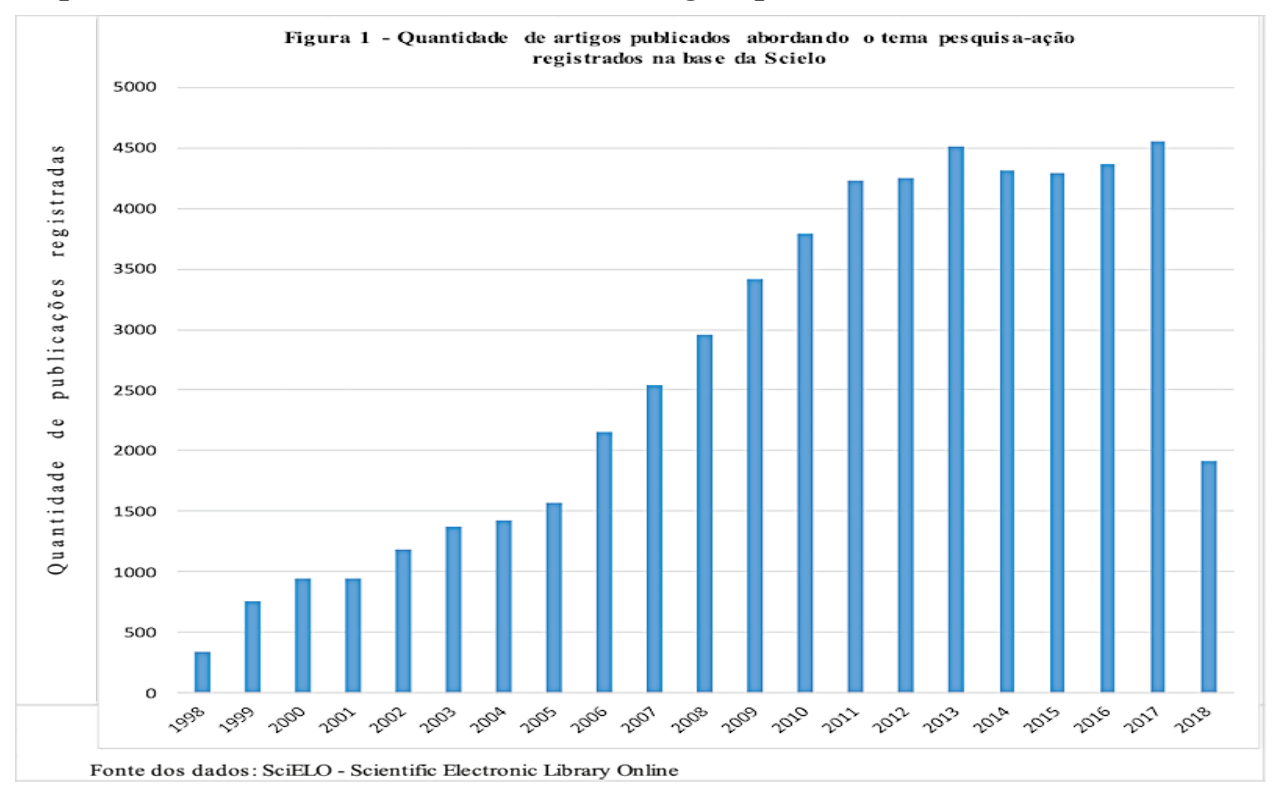

Observa-se também interesse cada vez maior sobre o tema ao longo dos anos no campo das ciências sociais aplicadas. De 1998 a 2010, nota-se crescimento constante na quantidade de artigos publicados, saindo de 344 artigos em 1998 e chegando a 3.797 artigos publicados no ano de 2010. Do ano de 2011 em diante, mais de quatro mil artigos são publicados anualmente, conforme a Figura 1. Até meados de 2018, foram publicados aproximadamente dois mil artigos, mantendo-se a média aproximada de quatro mil artigos por ano a partir de 1998. 
A despeito desses números, a opção nesta pesquisa, como mencionado na metodologia, foi pela realização de um estudo qualitativo e com mais profundidade do que em um estudo quantitativo. No entanto, a breve apresentação desse panorama das publicações sobre o tema pesquisa-ação na base de dados na Scielo mostra a pertinência de um estudo com base em dissertações e teses, mesmo porque muitos artigos científicos têm origem nesses trabalhos.

A leitura das dissertações e teses selecionadas para este estudo possibilitou seu enquadramento nas tipologias de Tripp (2005), ainda que em alguns casos se afastassem das acepções de pesquisa-ação em Thiollent (2011). Para fins didáticos, pode-se dividir essas pesquisas selecionadas em dois grupos principais: 1) visão prática e visão técnica; e 2) visão emancipável, visão política e visão crítico-social.

As visões técnicas e práticas puderam ser mais facilmente distinguidas, por meio da observação da intenção do autor de simplesmente implantar determinado "modelo" no espaço pesquisado (visão técnica) ou de proceder e propor um novo modelo ou uma nova técnica ou ideia a partir do estudo de outras existentes (visão prática). Quando se trata, porém, da adoção da pesquisa-ação numa visão emancipável, política ou crítico-social, as dificuldades aparecem com maior ênfase, pois nem sempre é possível caracterizar uma pesquisa em uma dessas perspectivas apenas ou mesmo delimitá-las dentro de uma visão.

Nesse sentido, o próprio Tripp (2005) diz ser a pesquisa críticosocial uma espécie de adoção da pesquisa-ação em uma visão política. Além disso, segundo o autor, a pesquisa-ação numa perspectiva emancipável é raramente utilizada, por ser mais ampla, indo além do sentido político ou crítico-social.

Apenas em oito casos estudados neste artigo, observou-se elementos suficientes para um convencimento de pesquisa-ação em sentido emancipável, ainda que de uma forma ou de outra o sentido emancipável resvale em outras visões, especialmente às de cunho político e crítico-social. As interpretações a seguir buscam caracterizar uma visão de pesquisa-ação que prepondera na dissertação ou tese estudada. No entanto, nas teses e dissertações analisadas, aparecem, amiúde, traços de mais de uma das visões identificadas por Tripp (2005). 


\section{Modos de uso da pesquisa-ação}

A leitura dos textos selecionados permitiu a apresentação de um leque de tipologias de pesquisa-ação que mostram seu uso em Administração. Em 43 dos 64 trabalhos analisados (67\%), a adoção da pesquisa-ação se deu associada às visões técnica e prática, sendo que em 22 desses 64 trabalhos (34\%), a adoção da pesquisa-ação pode ser associada ao sentido técnico, tendo em vista que os autores desses estudos partem de um método, de uma ideia ou de um processo já pronto ou idealizado para implantá-lo ou acompanhar uma implantação no espaço organizacional onde pesquisam

Em algumas pesquisas, ainda que o sentido técnico de pesquisa-ação pudesse ser visto, a observação mais detalhada permitiu identificar a preponderância da visão prática, no entendimento de que o pesquisador procurou, ao longo da pesquisa e junto com seus participantes, elaborar proposta ou solução para o problema de pesquisa. Dos 21 trabalhos analisados, em doze deles (33\%), foi possível identificar essa visão prática.

As pesquisas que se referem às visões política, crítico-social e emancipável totalizam $21 \%$, sendo que a linha que separa a definição de cada uma se mostra às vezes bem tênue. A visão política parece envolver mais acepções de mudança de cultura ou mudanças de ideias no ambiente pesquisado. Na visão crítico-social, isso também aparece, mas como uma espécie de intervenção no local de pesquisa, buscando mudanças nos modos de pensar, mas sobretudo de agir das pessoas, levando à transformação da realidade em que se encontram. Na visão emancipável, essas duas visões também parecem estar presentes, mas o que a caracteriza com maior força é a proposta de que as transformações nas formas de agir, de pensar e no espaço social pesquisado tenha como protagonistas as pessoas participantes da pesquisa e do local pesquisado e num âmbito maior. Para ilustrar como essas pesquisas costumam ser conduzidas, em seguida é feito descrição de algumas delas.

Em uma visão que pode ser caracterizada como emancipável do uso da pesquisa-ação, Affeldt (2011) desenvolve tese no contexto do ensino de Administração, defendendo que o enriquecimento da forma de ensinar Administração está pautado na utilização de um modelo que envolva o aluno em situações associadas à prática, por 
isso, um ensino de modo construtivista deve ser criado a partir de contextos, situações reais e problemas autênticos. $\mathrm{O}$ autor critica modelos atuais de ensino em Administração, por apresentarem-se limitados aos novos conhecimentos exigidos pelos profissionais, como o desenvolvimento de autonomia do estudante, elemento básico a sua capacidade para tomada de decisões e para sua socialização. A realização da pesquisa-ação na fase de diagnóstico do estudo deu-se por meio de entrevistas semiestruturadas a alunos com "melhores" e "piores" desempenhos no curso de Administração, mas o pesquisador procura envolver os alunos selecionados em todas as fases da pesquisa-ação. Pode-se dizer que a visão política e a visão emancipável da pesquisa-ação perpassam a tese de Affeldt (2011), visto que além de participarem do projeto de construção de um novo modelo de ensino para Administração baseado em valores como autonomia e emancipação, esses valores são desenvolvidos nos e pelos próprios alunos participantes da pesquisa.

O uso da pesquisa-ação, como feito por Affeldt (2011), parece um bom exemplo de exploração de acepções e significados que baseiam a técnica de pesquisa e pode servir como referência para quem pretende desenvolver estudos análogos, associados à visão política da utilização da pesquisa-ação. A amplitude da pesquisa de Affeldt (2011), o campo do ensino em Administração, ajuda a caracterizar a adoção da pesquisa-ação em sentido emancipável.

O potencial de transformação no campo da educação por meio do uso da pesquisa-ação tem sido objeto de estudos, como na pesquisa de Flessner e Stuckey (2014) que chegam a comentar que, devido à constatação do potencial da pesquisa-ação para capacitar educadores, criar mudanças duradouras nas escolas e ter impacto nos resultados da aprendizagem dos alunos, entre outros resultados positivos, lideranças escolares começam a exigir o uso da pesquisa-ação dentro de suas escolas. Esse potencial da pesquisa-ação gera, também, na visão dos autores, ideias contrárias ao seu uso, assim como tensões políticas, que são examinadas pelos autores em seu estudo.

Já em uma visão que parece mais política do uso da pesquisa-ação, o objetivo da pesquisa de Remonato (2011) é analisar como a distância tecnológica influencia na adoção de novas tecnologias no sistema de ensino de uma Instituição de Ensino Superior (IES) 
de um país em vias de desenvolvimento industrial (PVDI). Como resultados, o autor encontrou vários aspectos que podem interferir em um processo de internacionalização de um país desenvolvido industrialmente (PDI) para um país em vias de desenvolvimento industrial (PVDI). Em relação ao uso da pesquisa-ação, observase, como em outros casos, o desafio em compatibilizar o objetivo de pesquisa com a técnica de pesquisa. Nesse caso, a participação e a cooperação dos que fizeram parte da pesquisa restringiu-se as suas opiniões que, categorizadas, levaram ao alcance do objetivo da pesquisa. As opiniões dos participantes da pesquisa, por meio da aplicação de entrevistas, mostram conteúdos reflexivos e críticos e, dessa forma, alinham-se à visão política, uma vez que o processo de pesquisa, de uma forma ou de outra, vai produzir novos modos de pensar e de agir associados a significados que baseiam a pesquisa-ação.

Parecido ao sentido que Remonato (2011) concede à pesquisa-ação, Guerra (2012) explora o tema da administração estratégica, mais especificamente a formulação de estratégias, caracterizada como um processo de escolhas que culminará na estratégia da organização. Constituem objeto de pesquisa três casos oriundos de Instituições Científicas e Tecnológicas (ICT), de Minas Gerais, pioneiros na iniciativa de empreender organizações de alta tecnologia. O objetivo de pesquisa foi caracterizar o processo de formulação de estratégia de novos empreendimentos de alta tecnologia acadêmica. $\mathrm{O}$ autor utiliza a pesquisa-ação como meio de engajamento dos participantes da pesquisa, uma vez que os participantes são chamados a participar por meio de entrevistas abertas e participação em reuniões e seminários. Ainda que o autor tenha mencionado no referencial teórico elementos ligados à pesquisa-ação, como transformação da realidade, autonomia e práticas de liberdade, metodologia coletiva e participação efetiva da população na pesquisa, nota-se que o escopo e os objetivos de pesquisa não coadunam com esses aspectos. Assim, torna-se difícil caracterizar a pesquisa nas tipologias de Tripp (2005). Mas, em vista da atuação dos participantes da pesquisa em discussões, em reuniões, nas entrevistas e nos seminários, pode-se dizer que o uso da pesquisa-ação por Guerra (2012) tangencia a visão política. 
Assad (2012) adentra em sentidos ligados à adoção da pesquisa-ação numa visão crítico-social. O autor explora o problema habitacional, para quem, vem se configurando no mundo como um dos temas de maior relevância da atualidade. Assad (2012) se propõe a analisar desafios e oportunidades para a estruturação de negócios sociais na área da habitação no Brasil. Este tipo de negócio tem como objetivo principal contribuir para a resolução de algum problema social crítico, utilizando, para isso, mecanismos de mercado. Para atender seus objetivos, o autor realizou pesquisa-ação, na qual participaram moradores da Favela da Erundina, localizada na Zona Sul da cidade de São Paulo. No entanto, o autor se vê diante de desafios também associados à dificuldade de compatibilizar a pesquisa-ação com seu objetivo de pesquisa. Tal dificuldade aparece logo na ideia de utilizar a observação participante, o questionário e a entrevista, como procedimentos metodológicos para o desenvolvimento da pesquisa-ação, o que parece restringir sua adoção. No tocante aos resultados da pesquisa de Assad (2012), tendo a questão da reforma como foco específico de análise, foi possível constatar que os aspectos de assistência técnica em reforma, voltadas a demandas não coletivas; a disponibilidade de mão de obra qualificada; a gestão de materiais e o acesso a crédito, são os principais fatores críticos para a estruturação de um negócio social na comunidade voltado a esse fim.

\section{Panorama da pesquisa-ação na Administração}

Em termos quantitativos, as visões técnica e prática de pesquisa-ação são preponderantes no conjunto das dissertações e teses em Administração no Brasil. Como foi dito, dos 64 trabalhos pesquisados, nada menos que 43 absorvem a visão técnica ou prática de pesquisa-ação, ainda que nem sempre seja tarefa muito simples delimitar essas diferenças. Ou seja, aproximadamente dois terços dos trabalhos alinham-se a visões que se afastam relativamente de acepções e significados sociais e políticos originais que estruturam a ideia da pesquisa-ação.

No entanto, uma reflexão sobre pesquisas caracterizadas em uma visão emancipável, política ou crítico-social de pesquisa-ação (treze trabalhos dos 64 estudados) (Tabela 2), permite observar 
engajamento de pesquisadores no campo da Administração que percorrem os caminhos da mudança da realidade social e da emancipação e, com isso, mostram o potencial transformador da pesquisa-ação, algo que vem crescendo nos últimos anos, com crescimento significativo no ano de 2018. Nesse sentido, podem ser destacados os trabalhos de Assad (2012) e Affeldt (2011) como os que mais se aproximam de concepções originais da pesquisa-ação como método de investigação científica, assim como os trabalhos de Basso (2015) e Souza (2016).

Tabela 2 - Tipologias de Pes quis a-ação (TRIPP, 2005) obs ervadas em dis sertações e tes es em Adminis tração no Brasil defendidas nos anos 2011 a 2018

\begin{tabular}{|l|r|r|}
\hline \multicolumn{1}{|c|}{ Tipologia } & Quantidade & \% \\
\hline Visão Técnica de Pesquisa-ação & 22 & $34 \%$ \\
\hline Visão Prática & 21 & $33 \%$ \\
\hline Não identificada & 8 & $13 \%$ \\
\hline Visão Política & 4 & $6 \%$ \\
\hline Visão Crítico Social & 1 & $2 \%$ \\
\hline Visão Emancipável de Pesquisa-ação & 8 & $13 \%$ \\
\hline Total de trabalhos pesquis ados & $\mathbf{6 4}$ & $\mathbf{1 0 0 \%}$ \\
\hline Fon
\end{tabular}

Fonte dos dados: Catálogo de teses da CAPES

Observe-se que os trabalhos caracterizados como de uso técnico ou mecânico da pesquisa-ação mostram potencial restrito ou mesmo nulo de mudança. Isso porque, nota-se pouco envolvimento ou engajamento dos participantes na pesquisa, face, principalmente, à forma como o pesquisador conduz a investigação, ao deixar espaço reduzido para o envolvimento, cooperação e colaboração dos participantes. Na maioria dos casos, eles ficam restritos ao papel de fornecedores de informações para desenvolvimento ou implementação de determinado modelo ou técnica organizacional. Ou seja, ainda que esses estudiosos busquem engajamento de pessoas no sentido de atuarem na pesquisa para implantação de determinada técnica de gestão ou de proposição de uma nova, esse engajamento é prejudicado em razão da ausência dos participantes em etapas decisivas da pesquisa.

No que tange à localização dos trabalhos, há tendência nítida de desconcentração em diferentes instituições de ensino no Brasil, sem 
prevalência de uma ou outra. Também não se pode falar em uma tendência de crescimento do uso da pesquisa-ação em Administração, já que esse número veio aumentando progressivamente de 2011 a 2014, mas decresceu em 2015 a 2017 e se recuperou em 2018, como mostra a Tabela 3, ainda ao mesmo tempo em que mostra destaque do uso da pesquisa-ação em 2018, ano em que foi registrada a maior quantidade de trabalhos, 13 no total (20\%). Os temas pesquisados também são variados, dividindo-se em temáticas desde educação, capacitação, negócios sociais, passando por implementação de modelos e técnicas de gestão.

\begin{tabular}{|c|c|c|c|}
\hline Ano & Dis s ertações & Teses & Total \\
\hline 2011 & 4 & 1 & 5 \\
\hline 2012 & 9 & 1 & 10 \\
\hline 2013 & 5 & 3 & 8 \\
\hline 2014 & 9 & 3 & 12 \\
\hline 2015 & 6 & 0 & 6 \\
\hline 2016 & 1 & 2 & 3 \\
\hline 2017 & 2 & 5 & 7 \\
\hline 2018 & 9 & 4 & 13 \\
\hline Total de trabalhos pes quis ados & 45 & 19 & 64 \\
\hline
\end{tabular}

Para além de reflexões a respeito da hegemonia de visões técnicas e práticas de pesquisa-ação em Administração, os resultados desta pesquisa mostram o potencial e a força da pesquisa-ação na perspectiva qualitativa, o que se confirma no ano de 2018. Algumas sugestões de pesquisa surgem deste artigo, como, até que ponto a adoção da pesquisa-ação pelos autores dos trabalhos pesquisados neste artigo observam as acepções, as etapas e os métodos que a pesquisa-ação abrange. Outra questão que surge é o porquê de tantos trabalhos alinhados às visões prática e técnica de pesquisa-ação em Administração, quando o que se esperava era seu uso mais amplo nos sentidos emancipável, crítico-social e político.

\section{CONSIDERAÇõES FINAIS}

Este artigo teve como objetivo analisar os tipos de pesquisa-ação predominantes nas dissertações e teses em Administração 
no Brasil. As interpretações mostram dificuldades na tentativa de enquadramento dos estudos baseados na pesquisa-ação de acordo com as tipologias de Tripp (2005), mas, ao mesmo tempo, mostram a utilidade dessas tipologias para o entendimento dessas pesquisas. Os resultados revelam uma riqueza de experiências nas categorias estudadas, mas forte predomínio da visão técnica e prática de pesquisa-ação. Indicam a pouca utilização nos sentidos político e crítico-social, resultados que vão ao encontro da constatação da visão funcionalista hegemônica no campo da Administração.

Uma advertência que se pode fazer, é a evidência de que, em algumas pesquisas, o pesquisador parece "abandonar" a metodologia da pesquisa-ação, às vezes logo no seu início, ou durante seu processo de pesquisa. Em alguns trabalhos, observa-se referenciais teóricos aprofundados sobre a metodologia da pesquisa-ação, mas, paradoxalmente, o mesmo pesquisador parece não conseguir reunir teoria e prática e, assim, não consegue colocar em prática nos trabalhos de campo o potencial da pesquisa-ação. Em alguns trabalhos, por exemplo, o pesquisador não leva em consideração as fases necessárias ao processo da pesquisa-ação recomendadas por Thiollent (2011).

As interpretações apresentadas neste artigo possibilitam reflexões para melhor compreensão e aplicação da pesquisa-ação na Administração. Podem contribuir ainda, para a tomada de decisão sobre a aplicação ou não do método no estudo de determinado tema. Um tema ou pesquisa que se afaste de valores no campo da emancipação ou da crítica social, seja em qual área for, dificilmente redundará numa investigação exitosa. As reflexões realizadas neste trabalho também abrem perspectivas para investigação de outros problemas de pesquisa, por exemplo: Que caminhos ou desvios estão emergindo no uso da pesquisa-ação em Administração? Que novas visões podem ser pensadas para o uso da pesquisa-ação, além das identificadas na tipologia de Tripp (2005)?

Nos trabalhos pesquisados, dentre as tipologias de Tripp (2005), a visão prática é a que aparece mais difusiva, no sentido que parece ser utilizada de formas variadas, pois nem sempre o autor deixa claro de onde se inspirou ou trouxe a prática que pretendeu adotar por meio da pesquisa-ação. Esse entendimento remete à ideia de que outras tipologias podem ser pensadas a partir de um estudo 
minucioso desses trabalhos. De outro lado, ao falar das características da pesquisa-ação, Thiollent (2011) destaca o objetivo do método de servir para resolver ou esclarecer problemas de estudo, visando pretender aumentar conhecimento ou esclarecimento pelo pesquisador e pelas pessoas envolvidas na pesquisa, acerca de um problema pesquisado.

Essas observações substanciam o caminho para se pensar outras tipologias, no campo das pesquisas interpretativas, por exemplo. Como o próprio Thiollent (2011) adverte, a pesquisa-ação não se constitui limitadamente em meio ou forma de ação ou ativismo, pois visa aumento de compreensão dos envolvidos na pesquisa a respeito do objeto de pesquisa. Outras tipologias não foram apontadas neste artigo, pois isso não faz parte de seu escopo, mas é possível considerar como contribuição teórica deste trabalho, as descobertas, as orientações e pistas que as interpretações resultantes dos trabalhos analisados deixaram.

Outra contribuição deste artigo a área de Administração encontra-se no mapeamento de pesquisas que resultaram em teses e dissertações focos deste trabalho. Todas as pesquisas realizadas no período de 2011 a 2018, localizadas no banco de teses da CAPES, permite afirmar que a pesquisa bibliográfica realizada neste trabalho é abrangente, tem profundidade suficiente para o objeto de pesquisa formulado, produzindo esclarecimentos que podem ser úteis ao uso mais adequado do método da pesquisa-ação em investigações acadêmicas. Essa reflexão, aliás, para os autores deste trabalho, consiste em uma das principais contribuições do artigo para a área de Administração, aliada à abertura que este artigo traz à exploração de outras tipologias de pesquisa-ação que possam ser somadas à teoria existente. Ou seja, consistem esses resultados em inovações e diferenciais relevantes deste trabalho. Tendo em vista que a pesquisa-ação é considerada uma forma de pesquisa engajada (VAN DE VEN, 2007), onde a produção de conhecimento se dá ao mesmo tempo em que o processo de pesquisa contribui para tomada de decisões relativas a solução de problemas, os resultados deste trabalho servem ainda, para se refletir sobre qual é o tipo de engajamento produzido nas pesquisas enquadradas nas categorias de Tripp (2005). 
Embora a pesquisa-ação sofra uma certa resistência no mundo acadêmico por ser considerada uma ação profissional, de extensão ou de consultoria, contaminada por um viés ideológico, cuja metodologia não se enquadra dentre as metodologias de pesquisa convencionais (GREENWOOD, 2002; ANTUNES; MENDONÇA NETO; VIEIRA, 2016), bem como a dificuldade de se utilizar os resultados destas pesquisas para conceituações teóricas (HUXHAN, 2003), o que se pôde observar neste artigo, é que dentre os vinte periódicos que mais publicam pesquisas usando esta metodologia no campo da Administração, oito deles têm conceito A2 na classificação da CAPES. Tal fato pode servir para provocar reflexões sobre possíveis preconceitos em relação à relação à pesquisa-ação no mundo acadêmico e na área de Administração.

A perspectiva dos autores desta pesquisa é que este estudo possa chamar atenção para essas e outras questões e assim contribuir para o desenvolvimento de uma visão panorâmica e mais aprofundada do uso da pesquisa-ação em Administração. Desenvolvimento com vistas a aplicações que demonstrem o potencial técnico e social transformador desse método de investigação. Os resultados revelam o potencial da pesquisa-ação como método de pesquisa participativa no campo da Administração, ainda que ressalvas sejam feitas, como as que foram realizadas neste artigo. Esta pesquisa pode contribuir para adoção da pesquisa-ação em Administração com maior profundidade e qualidade, observando-se por parte dos pesquisadores, os elementos teóricos e procedimentais que a sustentam, principalmente no que tange a sua associação à crítica, à transformação social e à emancipação do ser humano.

\section{REFERÊNCIAS}

AFFELDT, F. S. Desenvolvimento e aplicação de um modelo construtivista para o ensino de Administração. 2011. 264 f. Tese (Doutorado em Administração) - Universidade Federal do Rio Grande do Sul, Porto Alegre.

ANTUNES, M. T. P.; MENDONCA NETO, O. R.; VIEIRA, A. M. Pesquisa Intervencionista e Mestrados Profissionais: perspectivas de sua prática nos cursos da área de gestão. Revista Indagatio Didactica, v. 8, p. 53-68, 2016

ARGYRIS, C.; SCHÖN, D. Theory in practice. São Francisco: Jossey Bass, 1974.

ASSAD, F. A. Negócios sociais no Brasil: oportunidades e desafios para o setor habitacio- 
nal. 2012. 143 f. Dissertação (Mestrado Acadêmico em Administração) - Universidade de São Paulo, São Paulo.

BALDISSERA, A. Pesquisa-ação: uma metodologia do "conhecer" e do "agir" coletivo. Sociedade em Debate, v. 7, n. 2, p. 5-25, ago. 2001.

BARBIER, R. A pesquisa-ação. Brasília: Liber Livro, 2007.

BASSO, B. L. Educação e construção de conhecimento: uma experiência no curso de graduação em administração. 2015. 169 f. Dissertação (Mestrado em Administração) - Universidade Federal do Rio grande do Sul, Porto Alegre.

BARDIN, L. Análise de Conteúdo. Lisboa: Edições 70, 2004.

BOGDAN, R. C.; BIKLEN, S. K. Investigação qualitativa em educação. Tradução Maria João Alvarez, Sara Bahia dos Santos e Telmo Mourinho Baptista. Porto: Porto Editora, 1994.

BURNS, A.; WESTMATCOTT, A. Teacher to Researcher: Reflections on a New Action Research Program for University EFL Teachers. Issues in Teachers' Professional Development, v. 1, p. 15-23, 2018.

CHIASSON, M.; GERMONPREZ, M.; MATHIASSEN, L. Pluralist action research: a review of the information systems literature. Information Systems Journal, v. 19, p. 31-54, 2009.

DURAK, G.; YÜNKÜL, E.; CANKAYA, S.; AKPINAR, S.; ERTEN, E.; INAM, N.; TAYLAN, U.; \& URFA, M. Content Analysis of Master Theses and Dissertations Based on Action Research. Journal of Education and Training Studies, v.4, n.12, p. 71-80, 2016.

FLESSNER, R.; STUCKEY, S. Politics and action research: An examination of one school's mandated action research program. Action Research, v. 12, n. 1, p. 36-51, 2014.

FULMER, G. W.; CHU, H.; MARTIN, S. N. The Potential of Teacher-Led Research: Teachers' Action Research Collaborations in Science Education in Singapore. Asia-Pacific Science Education, 2018, v. 4, n. 7, p. 2-6, 2018.

GONZÁLEZ REY, F. L. G. Pesquisa qualitativa em psicologia: caminhos e desafios. São Paulo: Thompson Learning, 2002.

GONZÁLEZ REY, Fernando Luis; MARTÍNEZ, Albertina Mitjáns. Subjetividade: teoria, epistemologia e método. Campinas: Editora Alínea, 2017.

GREENDWOOD, D. J. Action research: unfulfilled promises and unmet challenges. Concepts and Transformation, v. 7, n. 2, p. 117-139, 2002.

GUERRA, P. V. Formulação de estratégia em novos empreendimentos de base tecnológica de origem acadêmica. 2012. 143 f. Dissertação. (Mestrado Acadêmico em Administração) Universidade Federal de Minas Gerais, Belo Horizonte.

HAGUETTE, T. M. F. Metodologias qualitativas na sociologia. (5 ed). Petrópolis: Vozes, 1997.

HUXHAM, C. Action research as a methodology for theory development. Policy \& Politics, v. 31, n. 2, p. 239-248, 2003.

KHAN, K. S.; BAWANI, S. A. A.; AZIZ, A. Bridging the gap of knowledge and action: A case for participatory action research. Action Research, v, 11, n. 2, p.157-175, 2013. 
KEMMIS, S.; MCTAGGART, R. Participatory Action Research: communicative action and the public sphere. In: DENZIN, Norman K; LINCOLN, Yvonna S. (Eds.). The Sage handbook of qualitative research. 3. ed, p. 559-603, 2005

LEWIN, K. Teoria de campo em ciência social. São Paulo: Pioneira, 1965.

ACKE, J. A pesquisa-acão como estratégia de pesquisa participativa. In: GODOI, C. K. et al (Eds.). Pesquisa qualitativa em estudos organizacionais: paradigmas, estratégias e métodos. São Paulo: Saraiva, 2006, p. 206-239.

MARTÍNEZ, A. M.; REY, F. L. G. Subjetividade: teoria, epistemologia e método. Campinas: Alínea, 2017.

MELO, A. S. E.; MAIA FILHO, O. N.; CHAVES, H. V. Lewin e a pesquisa-ação: gênese, aplicação e finalidade. Fractal, Revista de Psicologia, v. 28, p. 1, p. 153-159, 2016.

NOVAES, M. B.; GIL, C. A pesquisa-ação participante como estratégia metodológica para o estudo do empreendedorismo social em administração de empresas. Revista de. Adminstração Mackenzie, v. 10, n. 1, p. 134-160, 2009.

PAES DE PAULA, A. P. Repensando os estudos organizacionais: por uma nova teoria do conhecimento. Rio de Janeiro: Editora FGV, 2015.

PAREDES-CHI, A. A.; CASTILLO-BURGUETE, M.T. Caminante no hay [un solo] camino, se hace camino al andan: Investigación Acción Participativa y sus repercusiones en la práctica. Revista Colombiana de Sociologia, v. 41, n. 1, p. 31-50, 2018a.

PAREDES-CHI, A. A.; CASTILLO-BURGUETE, M.T. Is Participatory Action Research an innovative pedagogical alternative for training teachers as researchers? The training plan and evaluation for normal schools. Evaluation and Program Planning, v. 68, p. 176-184, 2018b.

PINTO, J. B. G. Pesquisa-Ação: detalhamento de sua sequência metodológica. Recife, 1989, Mimeo.

REMONATO, R. L. C. A distância tecnológica na adoção de novas tecnologias no sistema de ensino de uma instituição de ensino superior em um país em vias de desenvolvimento industrial. 2011. 199 f. Dissertação (Mestrado Acadêmico em Administração) - Universidade Federal do Paraná, Curitiba.

SOUZA, M. M. P. de. Reciclando a crítica nos Estudos Organizacionais: As tecnologias de gestão colaborativa no contexto da Astriflores. 2016. 326 f. Tese (Doutorado em Administração) - Universidade Federal de Minas Gerais, Belo Horizonte.

TRIVIÑOS, A. N. S. Introdução à pesquisa em ciências sociais: a pesquisa qualitativa em educação. São Paulo: Atlas, 1992.

TEIXEIRA, P. M. M.; MEGID NETO, J. Sobre a pesquisa-ação nas dissertações e teses em ensino de biologia (1972-2011). Alexandria: Revista de Educação em Ciência e Tecnologia, v. 11, n. 1, p. 283-308, 2018.

THIOLLENT, M. Pesquisa-ação nas organizações. São Paulo: Atlas, 1998.

Metodologia da pesquisa-ação. 18a. ed. São Paulo: Cortez, 2011. 
TRIPP, D. Action research: a methodological introduction. Educação e Pesquisa, v. 31, n. 3, p. 443-466, set./dez. 2005.

VAN DE VEN, A. H. Engaged scholarship: a guide for organizational and social research. Oxford: Oxford University Press, 2007.

VIEIRA, A. M.; CASTRO, D. S. P.; OLIVEIRA, R. J. Políticas públicas integradas: conceitos, metodologias participativas e casos. São Bernardo do Campo: Editora Metodista, 2013.

YIGIT, C.; BAGCECI, B. Teachers' opinions regarding the usage of action research in professional development. Journal of Education and Training Studies, v. 5, n. 2, p. 243-252, 2017.

\section{APÊNDICE - RELAÇÃO DAS 64 DISSERTAÇÕES E TESES UTILIZADAS}

AFFELDT, Fabrício Sobrosa. Desenvolvimento e Aplicação de um Modelo Construtivista para o Ensino de Administração' 01/06/2011 264 f. Doutorado em Administração Instituição de Ensino: Universidade Federal do Rio Grande do Sul, Porto Alegre.

ALMEIDA, JOSE ALVARO JARDIM DE. Investigação Apreciativa integrada às práticas deGestão do Conhecimento em P\&D no Setor ElétricoBrasileiro: o caso da Companhia Hidro Elétrica do SãoFrancisco' 29/08/2013 199 f. Doutorado em Administração Instituição de Ensino: Universidade Federal de Pernambuco, Recife.

ANDRADE, SIMONE FONSECA DE. Desenvolvimento de inteligência competitiva no setor vitivinícola' 04/11/2014 178 f. Mestrado em Administração Instituição de Ensino: UNIVERSIDADE DE CAXIAS DO SUL, Caxias do Sul.

ASSAD, Fernando Amiky. Negócios sociais no Brasil: oportunidades e desafios para o setor habitacional' 01/02/2012 143 f. Mestrado em Administração Instituição de Ensino: UNIVERSIDADE DE SÃO PAULO, São Paulo.

AYRES, SIMONE MAIA PIMENTA MARTINS. Proposta de um sistema de capacitação baseada em competências para o Instituto Federal de Educação Ciência e Tecnologia do Sertão Pernambucano' 01/08/2012 176 f. Mestrado em Administração Instituição de Ensino: Universidade Federal da Paraíba/João Pessoa, João Pessoa.

BARROS, HEITOR CUNHA. Boas práticas da governança corporativa no processo de sucessão nas empresas familiares para a mitigação dos riscos' 12/11/2017 148 f. Mestrado Profissional em Administração Instituição de Ensino: Faculdade Pedro Leopoldo, Pedro Leopoldo.

BARROSO, ROSECLAIR DA ROCHA LACERDA. A gestão financeira e sua implicação no desempenho do negócio dos empreendedores no ramo da beleza da cidade de Sant'Ana do Livramento-RS' 16/03/2018 115 f. Mestrado em Administração Instituição de Ensino: Fundação Universidade Federal do Pampa, Sant'Ana do Livramento.

BASSO, BARBARA LORENZONI. Educação e construção de conhecimento: uma experiência no curso de graduação em Administração' 02/06/2015 169 f. Mestrado em Administração Instituição de Ensino: Universidade Federal do Rio Grande do Sul, Porto Alegre. 
BERTI, DEBORA ZANARDO. Análise da implantação da Metodologia Lean Sigma. A experiência de uma empresa de petróleo.' 29/08/2014 79 f. Mestrado Profissional em Administração Instituição de Ensino: Faculdade de Economia e Finança do IBMEC, Rio de Janeiro.

BOAVENTURA, EVALDO FERREIRA. Implementação do sistema Toyota sob a ótica da gestão de mudanças: uma pesquisa-ação aplicada ao Hospital Veterinário de Uberaba' 01/08/2011 175 f. Mestrado em Administração Instituição de Ensino: Universidade Federal de Uberlândia, Uberlândia.

BORGES, DENISE APARECIDA HIPOLITO. Muito mais que uma política: ações empreendedoras no esporte de Lavras/MG' 22/02/2018 101 f. Mestrado em Administração Instituição de Ensino: Universidade Federal de Lavras, Lavras.

BRAGA, GUSTAVO SIMOES. Inovação e Gestão de Processos de Negócios (BPM): uma metodologia adaptada para pequenas empresas' 25/03/2015 169 f. Mestrado em Administração Instituição de Ensino: Universidade Federal do Paraná, Curitiba.

CAMPOS, TEODORO MALTA. O coaching no desenvolvimento de competências empreendedoras: uma pesquisa-ação' 28/08/2014 234 f. Doutorado em Administração Instituição de Ensino: Universidade Nove de Julho, São Paulo.

COSTA, CASSIO HENRIQUE GARCIA. Modelo de gestão estratégica aplicado à agência de Inovação do Café (INOVACAFÉ)' 10/03/2017 266 f. Doutorado em Administração Instituição de Ensino: Universidade Federal de Lavras.

CUNHA, Gustavo Ananias. Sistema de suporte a decisão para formação de preço: um estudo de caso de uma empresa de locação de veículos.' 01/12/2012 145 f. Profissionalizante em Administração Instituição de Ensino: Faculdade Pedro Leopoldo, Pedro Leopoldo.

CZYKIEL, RENATA. Inserção da sustentabilidade no processo de formação do administrador: desvendando possibilidades' 20/06/2013 144 f. Mestrado em Administração Instituição de Ensino: Universidade Federal do Rio Grande do Sul, Porto Alegre.

DIAS, GABRIELA COSTA. Gerenciamento de riscos da cadeia de suprimentos de uma indústria automobilística com base na seleção de ferramentas da Norma ISO 31010' 16/04/2018 87 f. Mestrado Profissional em Administração Instituição de Ensino: Universidade Federal Fluminense, Volta Redonda.

FARES, FABIO ARANHA. Proposição de um planejamento estratégico, apoiado no BSC, para o serviço público: o caso do serviço de licenciamento de pequenas reformas no Município de Vitória' 01/10/2015 166 f. Mestrado em Administração Instituição de Ensino: Fundação Instituto Capixaba de Pesq.em Cont.Econ.e Finanças, Vitória.

FERNANDES, MARCIO GRIMA. A administração condominial à luz do custo para servir clientes: um estudo na Baixada Santista (SP)' 26/09/2013 117 f. Mestrado em Administração Instituição de Ensino: Universidade Municipal de São Caetano do Sul, São Caetano do Sul.

FILHO, MARIO MANNARINO. Sequenciamento de produção e logística Fuzzy: incorporando elementos de gestão de estoque' 21/08/2014 75 f. Mestrado em Administração Instituição de Ensino: Universidade Federal do Rio de Janeiro, Rio de Janeiro.

FILHO, VALTER JOBIM MEYER. Modelo multicritério construtivista de avaliação de desempenho para apoiar a gestão dos programas de benefícios de medicamentos pbms na perspectiva social' 30/08/2018 99 f. Mestrado em Administração Instituição de Ensino: Universidade do Sul de Santa Catarina, Tubarão. 
FRAGA, BRENDOW DE OLIVEIRA. Coprodução do plano de desenvolvimento com base nos princípios SLOW: pesquisa-ação em rio doce (MG) Brasil' 19/02/2018 206 f. Mestrado em Administração Instituição de Ensino: Universidade Federal de Viçosa, Viçosa Biblioteca.

GARCIA, ALANNA THAYSA DE OLIVEIRA. Gestão de pessoas por competências em pequenas empresas: uma abordagem multimétodo' 05/08/2016 235 f. Doutorado em Administração Instituição de Ensino: Universidade De São Paulo, São Paulo

GOMES, Frederico Pessanha. Proposta de configuração de rede logística reversa para a coleta de resíduos do setor moveleiro da região metropolitana de Curitiba' 01/03/2011 113 f. Mestrado em Administração Instituição de Ensino: Pontifícia Universidade Católica do Paraná, Curitiba.

GONÇALVES, Eduardo Jardel Veiga. Análise e desenvolvimento de modelos de negócio em Spin-Offs acadêmicos: um estudo junto a empresas da Inbatec Ufla' 01/07/2012 129 f. Mestrado em Administração Instituição de Ensino: Universidade Federal de Lavras, Lavras.

GONZALES, ROGERIO LEITE. Aprendizagem Baseada em Projetos: uma Pesquisa Ação Participante no processo de ensino/aprendizagem de Sustentabilidade no curso de Administração de Empresas' 12/04/2018 193 f. Mestrado em Administração Instituição de Ensino: Universidade Federal do Rio Grande do Sul, Porto Alegre.

GUERRA, Paulo Vítor. Formulação de estratégia em novos empreendimentos de base tecnológica de origem acadêmica.' 01/06/2012 143 f. Mestrado em Administração Instituição de Ensino:Universidade Federal de Minas Gerais, Belo Horizonte.

JOHANN, ELENILTON RUDIGER. Proposta de método para priorização dos derivativos no gerenciamento do risco em operações de troca no mercado de commodities agrícolas por meio de análise multicritério: um estudo de caso na empresa Alfa' 29/09/2014 undefined f. Doutorado em Administração Instituição de Ensino: Pontifícia Universidade Católica do Paraná, Curitiba.

JUNIOR, LUIZ ANTONIO BLOEM DA SILVEIRA. Aplicação de técnicas de previsão tecnológica visando reduzir o peso de amortecedores' 03/10/2013 218 f. Mestrado em Administração Instituição de Ensino: Universidade de São Paulo, São Paulo.

JUNIOR, ROBERTO DA LUZ. Planejamento estratégico como ferramenta para a definição de estratégias conjuntas para o setor de saúde SUS de Santa Maria - RS' 01/08/2014 152 f. Doutorado em Administração Instituição de Ensino: Universidade de São Paulo, São Paulo.

JUNIOR, Sergio Satt. Construção de cenário para refinarias de petróleo com baixa escala e não integradas: um estudo de caso' 01/07/2012 115 f. Mestrado em Administração Instituição de Ensino: Universidade do Vale do Rio dos Sinos, São Leopoldo.

KUHN, MARISA CANELLO. O desenvolvimento da empatia em um grupo de trabalhadores na perspectiva teórico-metodológica da clínica psicodinâmica do trabalho' 17/04/2017 undefined f. Mestrado em Administração Instituição de Ensino: Fundação Universidade de Passo Fundo, Passo Fundo.

LIMA, WALERIA DE CASSIA SOUZA. Accountability na Gestão do Processo de Aprendizagem no IFBA, Campus de Salvador.' 22/08/2014 105 f. Mestrado Profissional em Administração Instituição de Ensino: Universidade Federal da Bahia, Salvador. 
LODI, MARLUCE DANTAS DE FREITAS. Consumo de alimentos e obesidade na perspectiva transformativa do consumidor' 22/02/2018 194 f. Doutorado em Administração Instituição de Ensino: Universidade do Grande Rio - Prof. José de Souza Herdy, Rio de Janeiro.

MACHADO, PAULO ROBERTO SILVEIRA. Modelo de gestão de compras em institutos de pesquisa' 14/12/2018 138 f. Mestrado em Administração Instituição de Ensino: Universidade Federal de Santa Maria, Santa Maria.

MARQUES, GUARANY OLIVEIRA. Gestão social ou gestão estratégica: um estudo sobre as práticas gerenciais em cooperativas sociais do Ceará' 23/03/2017 100 f. Mestrado em Administração Instituição de Ensino: Universidade Estadual do Ceará, Fortaleza.

MARTINEZ, Ramses Henrique. Processo judicial eletrônico: uma abordagem metodológica para o processo de sua implementação' 01/05/2012 333 f. Doutorado em Administração Instituição de Ensino: Universidade de São Paulo, São Paulo.

MAZZONI, ANTONIO CARLOS CHEDE. Uma contribuição ao processo decisório de investimentos: utilização da pesquisa-ação com aplicação do método do fluxo de caixa descontado em uma revenda de veículos comerciais' 05/02/2014 143 f. Mestrado Profissional em Administração Instituição de Ensino: Universidade Metodista de Piracicaba, Piracicaba.

MEDEIROS, ANDRE LUIZ. Alocação de equipes de campo para avaliação de perdas não técnicas de energia elétrica: desenvolvimento de um sistema de apoio à decisão' 28/02/2013 186 f. Doutorado em Administração Instituição de Ensino: Universidade Federal de Lavras, Lavras Biblioteca.

MELLO, MARCELO BAILAO. Planejamento integrado de vendas, operações e econômico: um estudo de caso em uma empresa do setor de alimentação em shopping de Belo Horizonte - MG' 26/11/2015 undefined f. Mestrado Profissional em Administração Instituição de Ensino: Centro Universitário UNA, Belo Horizonte.

MELO, TERESA JULIA DE ARAUJO. Utilidade social em empreendimentos da economia solidária: o caso das mulheres do artesanato (Natal/RN).' 29/06/2018 undefined f. Mestrado em Administração Instituição de Ensino: Universidade Federal do Rio Grande do Norte, Natal.

MORAES, MARILDA SCHILLER DE. Coaching ontológico: uma contribuição à gestão hospitalar' 17/09/2015 149 f. Mestrado em Administração Instituição de Ensino: Pontifícia Universidade Católica de São Paulo, São Paulo.

MOREIRA, GEOVANA ANDREA. Percepção sobre a comunicação entre profissionais de saúde em um hospital de Lauro de Freitas-BA: estudo de caso' 27/08/2015 127 f. Mestrado em Administração Instituição de Ensino: Universidade Salvador, Salvador.

MOREIRA, KATIA DENISE. Proposição Metodológica para o Desenvolvimento de Competências Secretariais no Contexto da Gestão Universitária' 10/10/2018 301 f. Doutorado em Administração Instituição de Ensino: Universidade Federal de Santa Catarina, Florianópolis.

OLIVEIRA, RODRIGO BATISTA DE. Proposta de diretrizes para o processo de benchmarking no refino brasileiro' 24/02/2014 203 f. Mestrado Profissional em Administração Instituição de Ensino: Faculdade de Economia e Finanças do IBMEC, Rio de Janeiro.

PENHA, RENATO. Modelo computacional para alocação de recursos humanos em múltiplos projetos' 13/03/2018 241 f. Doutorado em Administração Instituição de Ensino: Universidade Nove de Julho, São Paulo. 
PENTEADO, MARCUS TEIXEIRA. Marketing de relacionamento - uma ferramenta para as instituições de ensino superior : estudo sobre portal institucional' 24/05/2013 $104 \mathrm{f}$. Mestrado em Administração Instituição de Ensino: Universidade Católica de Santos, Santos.

PINTO, EMELINE DE ABREU PEREIRA. E-mail marketing para participação social: aplicações e análises no Setor Público' 22/02/2016 98 f. Mestrado em Administração Instituição de Ensino: Universidade Federal de Lavras, Lavras.

REINECKE, LUIZ FILIPE GOLDFEDER. Desenvolvimento de metodologia de avaliação formativa de projetos: o caso do projeto "ações integradas de economia solidária" no município de Itajaí/SC' 02/06/2014 176 f. Mestrado Profissional em Administração Instituição de Ensino: Universidade do Estado de Santa Catarina, Florianópolis.

REIS, LUCIANA PAULA. Definição do modelo de negócio em empresas de base tecnológica: um processo de decisão baseado no método Analytic Hierarchy Process (AHP)' 06/06/2013 187 f. Doutorado em Administração Instituição de Ensino: Universidade Federal De Minas Gerais, Belo Horizonte.

REMONATO, ROBERTO LUIZ CUSTÓDIO. A distância tecnológica na adoção de novas tecnologias no sistema de ensino de uma instituição de ensino superior em um país em vias de desenvolvimento industrial' 01/04/2011 199 f. Mestrado em Administração Instituição de Ensino: Universidade Federal do Paraná, Curitiba.

ROCHA, ANDERSON FABIANO SANTANA. Gestão do Conhecimento: Processo de Implantação do Programa Mentor Petrobras na UO-SEAL.' 11/08/2014 111 f. Mestrado Profissional em Administração Instituição de Ensino: Universidade Federal da Bahia, Salvador.

ROSENBLATT, Lúcia. “Incorporação da dinâmica de sistemas ao processo de planejamento de marketing de uma empresa do setor industrial."' 01/06/2012 71 f. Profissionalizante em Administração Instituição de Ensino: Faculdade de Economia e Finanças do IBMEC, Rio de Janeiro.

SALES, VINICIUS VIEIRA. A gestão de ideias como catalisador da inovação em uma organização do setor de energia' 28/06/2017 206 f. Mestrado Profissional em Administração Instituição de Ensino: Centro Universitario UNA, Belo Horizonte.

SANTOS, GRAZIELLI FARIA ZIMMER. Em busca da efetividade na Administração Pública: proposição de uma metodologia para design e implementação de serviços públicos no município de Florianópolis' 24/10/2014 246 f. Mestrado Profissional em Administração Instituição de Ensino: Universidade do Estado de Santa Catarina, Florianópolis.

SCHILLING, LUIZ FERNANDO. A execução da estratégia na implantação de um produto de assistência à saúde para o mercado de baixa renda' 03/07/2013 88 f. Mestrado Profissional em Administração Instituição de Ensino: Universidade Federal do Rio Grande do Sul, Porto Alegre.

SILVA, Estevão Pereira da. Implementação da produção enxuta em uma pequena empresa da construção civil: um roteiro para a pré-implementação' 01/07/2012 120 f. Mestrado em Administração Instituição de Ensino: Universidade do Vale do Itajaí, Itajaí.

SILVA, FRANCISCO RANIERE MOREIRA DA. Gestão do desenvolvimento territorial em empreendimentos de habitação social no Brasil' 31/03/2017 201 f. Doutorado em Administração Instituição de Ensino: Universidade Federal da Bahia, Salvador. 
SILVA, MARCUS VINICIUS CESSO DA. Avaliação contínua e automatizada da produtividade acadêmica de cursos de graduação' 26/10/2017 105 f. Mestrado em Administração Instituição de Ensino: Universidade Nove de Julho, São Paulo.

SOUZA, MARIANA MAYUMI PEREIRA DE. Reciclando a crítica nos Estudos Organizacionais: As tecnologias de gestão colaborativa no contexto da Astriflores.' 25/11/2016 326 f. Doutorado em Administração Instituição de Ensino: Universidade Federal de Minas Gerais, Belo Horizonte.

TREVISANUTO, MARIANA FORLIN. Colaboração no front end da inovação: Um modelo de intervenção para promover a identificação e análise de oportunidades de forma colaborativa na Cianet' 13/08/2018 150 f. Mestrado Profissional em Administração Instituição de Ensino: Universidade do Estado de Santa Catarina, Florianópolis.

VANDERLEI, CELSO ARRUDA. Análise de patentes por mapas mentais automatizados no desenvolvimento do conhecimento organizacional' 20/12/2018 155 f. Doutorado em Administração Instituição de Ensino: Universidade Nove de Julho, São Paulo.

VENTURI, LILIAN. Gestão de resíduos sólidos em universidade: um estudo a partir da política nacional de resíduos sólidos' 29/05/2014 197 f. Mestrado em Administração Instituição de Ensino: Universidade Municipal de São Caetano do SuL, São Caetano do Sul.

ZOPPI, CINTIA. Planejamento e gestão de eventos no marketing educacional: um modelo para instituição pública educacional' 28/02/2013 94 f. Mestrado Profissional em Administração Instituição de Ensino: Universidade Metodista de Piracicaba, Piracicaba.

\section{Rogério Zanon da Silveira}

Universidade Federal do Espírito Santo. Doutor em Administração pela Universidade Federal de Minas Gerais (CEPEAD-UFMG - 2015). Mestre em Administração pela Universidade Federal do Espírito Santo (PPGADM-UFES) (2010) e Mestre em Ciências Contábeis pelo Instituto Nelson Abel de Almeida, ES (2003). Pós-graduado em Integração Econômica e Direito Internacional Fiscal pela Escola de Administração Fazendária (ESAF) (2005). Pós-graduado em Política e Estratégia Empresarial e graduado em Ciências Contábeis pela Universidade Cândido Mendes (2000). Auditor Fiscal da Receita Estadual do Estado do Espírito Santo, carreira na qual ingressou em 1984 por concurso público. Professor Adjunto da Universidade Federal do Espírito Santo (2015). Professor Permanente do Mestrado Profissional em Planejamento e Gestão Pública (UFES) e professor da Faculdade Pio XII de Cariacica (2012). Membro do Instituto Histórico e Geográfico do Espírito Santo. Autor dos livros Tributo, Educação e Cidadania e O IVA no Brasil, editados pelo IHGES. Interesse de pesquisa: Administração Pública. Participação, democracia e subjetividade nas organizações públicas e privadas.

\section{Marcia Prezotti Palassi}

Universidade Federal do Espírito Santo. Pós-doutorado em Psicologia Social na Universidad Complutense de Madrid/Espanha (2012). Doutorado em Psicologia Social pela Pontifícia Universidade Católica de São Paulo - PUC (2004). Mestrado em Psicologia pela Universidade Federal do Espírito Santo - UFES (1998). Especialização em Administração de Recursos 
Humanos pela Faculdade Espírito Santense de Administração - FAESA (1990). Graduação em Administração de Empresas pelo Centro Superior de Ciências Sociais de Vila Velha - UVV (1988). Foi professora visitante do Departamento de Psicologia Social da Universidade Autonoma de Barcelona/Espanha - UAB, atuando na linha de pesquisa sobre Psicologia Social do Trabalho, durante o doutorado-sanduíche (2002). Em 2001 foi cofundadora da Associação Brasileira de Psicologia Política - ABPP e da Revista Psicologia Política mantida pela ABPP. Em 2003 recebeu o Prêmio Ser Humano da Associação Brasileira de Recursos Humanos - ABRH/ ES. A partir de 2005 tornou-se professora do Departamento de Administração e do Programa de Pós-Graduação em Administração da Universidade Federal do Espírito Santo - PPGADM/ UFES. Neste programa, atuou como Coordenadora do Núcleo de Estudos em Tecnologias de Gestão e Subjetividades - NETES/UFES, no período de fevereiro/2005 à fevereiro/2009. Em 2008 tornou-se ainda, Professora do Programa de Pós-Graduação em Ciências Socias - PPGCSO/ UFES e pesquisadora do Laboratório de Estudos Políticos - LEP/UFES. A partir de março/2009 passou a coordenar o Observatório de Práticas Participativas vinculado ao PPGADM/UFES (https://www.nepsufmg.com.br/observatorio-de-praticas-participat) e ao Núcleo de Estudos em Participação e Subjetividades - NEPS, do qual é Líder2, vice-coordenadora. Em 2010 obteve o Prêmio ANPAD de Melhor Trabalho na Divisão Acadêmica de Estudos Organizacionais do EnANPAD 2010. Foi Vice-Presidente Região Sudeste da Associação Brasileira de Psicologia Política (Agosto/2011 a Outubro/2014), sendo reeleita para o próximo biênio (2015-2016). Tem experiência na área de Administração, Psicologia Social do Trabalho e Psicologia Política, atuando principalmente nos seguintes temas: estudos organizacionais, privatização, trabalho, consciência política, subjetividade, democratização da administração e gestão, participação das pessoas nas organizações, nos mecanismos participativos na administração pública e em ações coletivas nos setores público, privado e terceiro setor.

\section{Ana Paula Paes de Paula}

URL https://www.nepsufmg.com.br/

Universidade Federal de Minas Gerais. É Pós-Doutoranda em Administração pela EAESP-FGV (2005), Doutora em Ciências Sociais pelo IFCH-UNICAMP (2003) e Mestre em Administração Pública e Governo pela EAESP-FGV (1998). Realizou formação teórica em Psicanálise no Círculo Psicanalítico de Minas Gerais (CPMG) (2009-2014) e foi Professora Residente do IEAT-UFMG (2014-2015). Atualmente é Professora Titular e Pesquisadora da FACE-CEPEAD-UFMG, além de Colaboradora do PPG-ADM UFES. É coordenadora do Núcleo de Estudos em Participação e Subjetividade (NEPS) e do Observatório de Práticas Participativas (OPP). Trabalha principalmente com os seguintes temas: Movimentos Sociais, Participação Social e Ciberdemocracia; Experiências Alternativas, Economia Solidária e Tecnologias Sociais; Gestão Dialógica, Gestão Colaborativa e Autogestão; Subjetividade, Psicossociologia e Psicanálise de Grupos e Organizações.

Recebido em: 18-3-2019

Aprovado em: 18-9-2019

Avaliado pelo sistema double blind review.

Editor: Coordenação do PPGA/UMESP

Disponível em http://mjs.metodista.br/index.php/roc 